\title{
Membrane development for applications in hydrogen production using the sulphur-iodine thermochemical route
}

\section{Soumitra Kar*, R.C. Bindal, S. Prabakar and P.K. Tewari}

Desalination Division,

Bhabha Atomic Research Centre,

Trombay, Mumbai - 400085, India

E-mail: soubiswa@barc.gov.in

E-mail: bindal@barc.gov.in

E-mail: sprabha@barc.gov.in

E-mail: pktewari@barc.gov.in

*Corresponding author

\section{S. Ramanathan}

Materials Processing Division,

Bhabha Atomic Research Centre,

Trombay, Mumbai - 400085, India

E-mail: srama@barc.gov.in

\section{Jeetendra Nuwad and C.G.S. Pillai}

Chemistry Division,

Bhabha Atomic Research Centre,

Trombay, Mumbai - 400085, India

E-mail: nuwad@barc.gov.in

E-mail: cgspil@barc.gov.in

\begin{abstract}
Careful optimisation of a safe and sustainable route for hydrogen production is a pressing need. Thermochemical processes employing water as raw material and nuclear/renewable energies as energy source are believed to be the best possible option in this direction, while alarming issues such as climate change and global warming are being taken into account. Amongst the well-identified cycles, the sulphur-iodine (S-I) thermochemical route assumes the highest thermal efficiency and the best one as regards its coupling to a high temperature nuclear reactor. Material development is the key issue to be addressed to realise successfully the potential of the S-I cycle. The most important area is development of gas-permeable membranes for enhancement of the equilibrium decomposition of HI, which is the most intricate step as far as the overall process efficiency is concerned. In order to overcome the low efficiency associated with the low equilibrium decomposition of HI, the authors intend to develop a hydrogen permselective membrane reactor. As a first step towards this development, a silica membrane of asymmetric nature was developed using sol-gel processing and dip coating, and characterised using scanning electron microscopy and a BET surface area analyser. A road map
\end{abstract}


towards realising the successful emergence of the membrane reactor is discussed.

Keywords: nuclear hydrogen production; thermochemical cycle; membrane reactor.

Reference to this paper should be made as follows: Kar, S., Bindal, R.C., Prabakar, S., Tewari, P.K., Ramanathan, S., Nuwad, J. and Pillai, C.G.S. (2011) 'Membrane development for applications in hydrogen production using the sulphur-iodine thermochemical route', Int. J. Nuclear Hydrogen Production and Applications, Vol. 2, No. 3, pp.227-236.

Biographical notes: Soumitra Kar is a Scientist working in the Desalination Division of BARC. He is associated with the development of inorganic and organic membranes and membrane-assisted physicochemical processes for gas separation, water purification and effluent treatment. He is also actively involved in the development of carbon nanotube-based separation systems. He has about seven scientific papers to his credit. He is a Life Member of the Indian Desalination Association

R.C. Bindal is a Senior Scientist in the Desalination Division of BARC. He has been associated with the development of different types of membranes and membrane-based water purification devices. His major contribution is the development of an online domestic water purifier, which is an absolute barrier for pathogens. He has three patents and 25 publications to his credit.

S. Prabhakar is the Head of the Separation Technology Section, Desalination Division, BARC. He has been involved in the development and deployment of membrane-based technologies for desalination and water purification. He has been associated at the national level in many committees in pursuit of providing safe drinking water. He has filed three patents and is author of more than 75 scientific papers.

P.K. Tewari is the Head of the Desalination Division of BARC. He is the President of the Indian Desalination Association and sits on the Board of Directors of the International Desalination Association. He is the Chairman of the International Nuclear Desalination Advisory Group (INDAG) of the International Atomic Energy Agency (IAEA). He has been involved in providing consultancy services to several organisations on desalination and water purification. He has over 100 research publications to his credit in journals, proceedings, books and encyclopaedias. He is the Co-Chairman of the Editorial and Scientific Committee of the International Journal of Nuclear Desalination, and member of the Editorial Board of Desalination and water Treatment Science and Engineering.

S. Ramanathan joined the Metallurgy Division, BARC, after completing the 19th batch orientation course, and has been working on processing of advanced ceramics. He has specialised in the development of solid oxide electrolytes for oxygen sensor, silicon carbide ceramics and sol-gel processing for powders, coating and monoliths. Synthesis and evaluation of nanocrystalline oxide powders for applications in radionuclide absorption studies, radiation dosimetry and glass polishing have also been carried out. The thermal evolution of pore-size distribution by SANS studies in the nanocrystalline oxides has been carried out, and correlated with the sinterability. His current interest is on the synthesis of oxide powders with tailored characteristics and aqueous slurry-based processing of self-standing/supported films and tubes for SOFC application. He is also interested in the thermal decomposition and phase 
evolution behaviour in precursors formed by solution-based preparation techniques (e.g., sol-gel, co-precipitation and gel combustion). He is the author of more than 70 scientific papers.

Jitendra Nuwad graduated from MDS University, India, in 2000, and pursued the degree of MCA from MLS University, India. He joined the Chemistry Division, BARC, in 2002. Currently he is pursuing an MSc in Chemistry from Mumbai University by research. He has done synthesis of nanocrystalline semiconductors (II-VI system) and electrochemical deposition of diamond-like carbon films (DLC) and $\mathrm{CNx}$ at low voltage and metal nanodendrites. The work has been published in international peer-reviewed journals. Presently he is working in the field of chemical vapour deposition (CVD) of bulk diamond thin films, nanocrystalline diamond, and ballas-like diamond and their applications. He is author of more than 20 scientific papers.

C.G.S. Pillai joined BARC in 1976 from the 19th batch of BARC training school after completing his MSc (Physics) from Kerala University. He initiated his research career with developing a high temperature thermal conductivity measurement setup for solid samples. He obtained his $\mathrm{PhD}$ in 1987 from Bombay University. His main fields of research are electrical, thermal transport and thermophysical properties of solids, especially reactor fuel materials, development of diamond thin-film-based devices for their application as radiation detectors, and studies on solid-state hydrogen storage materials. He is author of more than 100 scientific papers.

\section{Introduction}

Global warming and climate change needs the urgent employment of non-fossil based sources of energy production. An intelligent obvious option in this direction is hydrogen economy. Thermochemical cycle using water as raw material and nuclear/renewable energies as sources of energy is believed to be a safe, stable and sustainable route of hydrogen production. Amongst the well-studied thermochemical cycles, the sulphur-iodine (S-I) cycle (Goldstein et al., 2005; Nomura et al., 2005) is capable of achieving an energy efficiency of 50\%, making it one of the most efficient cycles among all water-splitting processes. In addition, this cycle is the best possible one as regards to its coupling with high temperature nuclear reactor is concerned. The S-I cycle is similar to other chemical production processes in that it is highly suitable to scaling up to large-scale production of hydrogen.

The SI cycle is characterised by three basic reactions as shown below.

$$
\begin{aligned}
& \mathrm{I}_{2}+\mathrm{SO}_{2}+2+\mathrm{H}_{2} \mathrm{O} \rightarrow 2 \mathrm{HI}_{\mathrm{x}}+\mathrm{H}_{2} \mathrm{SO}_{4}\left(120^{\circ} \mathrm{C}\right) \\
& 2 \mathrm{H}_{2} \mathrm{SO}_{4} \rightarrow 2 \mathrm{SO}_{2}+2 \mathrm{H}_{2} \mathrm{O}+\mathrm{O}_{2}\left(830^{\circ} \mathrm{C}\right) \\
& 2 \mathrm{HI}_{\mathrm{x}} \rightarrow \mathrm{I}_{2}+\mathrm{H}_{2}\left(450^{\circ} \mathrm{C}\right)
\end{aligned}
$$

The high reaction temperature environment and the chemicals associated in the S-I cycle pose a very corrosive working environment. Effective realisation of a safe hydrogen production plant requires careful selection and optimisation of materials involved within each section of S-I cycle. The third section, that is the $\mathrm{HI}_{\mathrm{x}}\left(\mathrm{HI}+\mathrm{I}_{2}+\mathrm{H}_{2} \mathrm{O}\right)$ processing 
section, is the most intricate step in terms of the process efficiency as it has the lowest over all rate and very complicated separations. In order to overcome the low efficiency due to the poor equilibrium decomposition of HI, ongoing research is dedicated towards development of a hydrogen permselective membrane (Pakizeh et al., 2007; de Vos and Verweij, 1998). Proper identification of suitable membranes is proposed to improve the efficiency of the overall cycle and make hydrogen production more economical. The present paper is an attempt in this direction for development of silica-membrane on alumina support with graded porosity using sol-gel processing. The authors intend to use the membrane in the form of a packed bed membrane reactor for the enhancement of equilibrium decomposition of HI. The experimental procedure optimised towards development of an asymmetric silica membrane is cited here followed by a discussion on the possible fabrication of a membrane reactor after the chemical and stability of membranes being ascertained.

\section{Experimental}

The silica sol was prepared (de Vos and Verweij, 1998) by acid catalysed hydrolysis and condensation of tetraethylorthosilicate (TEOS, Fluka) in ethanol as follows. A mixture of acid and water was carefully added to a mixture of TEOS and ethanol under vigorous stirring. During the addition of the acid-water mixture, the TEOS-ethanol mixture was placed in ice-bath to avoid premature (partial) hydrolysis. After the addition was complete, the reaction mixture was refluxed for 3 hours at $60^{\circ} \mathrm{C}$ in a water bath under continuous stirring. The reaction mixture had a final molar TEOS:ethanol:water:acid ratio (based on unreacted components) of 1:3.8:6.4:0.085.All processing steps were well controlled.

Zeta potential measurements of alumina and silica sol were carried out with Zetasizer 3000 (Malvern). The average pore size determination of alumina was made with mercury porosimeter (Micromeritic). The specific surface area was determined by surface area analyser (Sorptomatic 1990). A detailed study on the surface morphology and cross-sections of monoliths and membranes were studied by scanning electron microscope (Seron AIS-2100) between 5 to $30 \mathrm{keV}$.

\section{Results and discussion}

The developmental step to obtain an alumina-silica composite membrane was worked out using dip coating technique on a highly porous alumina fibre board support. Alumina slurry was prepared under an optimised dispersion condition which was obtained through detailed zeta potential (z.p. at a pH of 3 was $\sim 40 \mathrm{mV}$, Figure 1) and viscosity (50 Vol. \% solid content) studies using alumina powder (ALCOA) with size $\mathrm{D}_{50}$ of $300 \mathrm{~nm}$ (Figure 2).

The average pore diameter of unsupported alumina layer was found to be $0.1 \mu \mathrm{m}$ from mercury porosimeter (Figure 3). Conditions were optimised for sintering of the layer to improve adherence and formation of the graded composite structure without cracks. The pore size varied across the cross section from $100 \mathrm{~nm}$ for the coated slurry surface to ten microns on the surface of the fibre board. Formation of silica film (with pores in the size of about $1.6 \mathrm{~nm}$ ) on the alumina support with graded porous structure 
was studied using a silica sol. The zeta potential of silica sol was found out to be $-7.8 \mathrm{mV}$ at $\mathrm{pH} 3$ (Figure 4). The particle size of the silica was found to be $\sim 2 \mathrm{~nm}$ from Zetasizer. The specific surface area was found to be about $55 \mathrm{~m}^{2} / \mathrm{g}$ by Brunaver-Emmett-Teller (BET) technique using nitrogen adsorption-desorption isotherms at $\mathrm{P} / \mathrm{P}_{0}$ of 0.01 to 0.995 at $77 \mathrm{~K}$. Pore volume was obtained considering the amount of nitrogen adsorbed. The average pore diameter was found to be about $1.6 \mathrm{~nm}$ by Barret-Joyner-Halenda (BJH) method.

Figure 1 Zeta potential of alumina slurry at $\mathrm{pH}=3$ (see online version for colours)

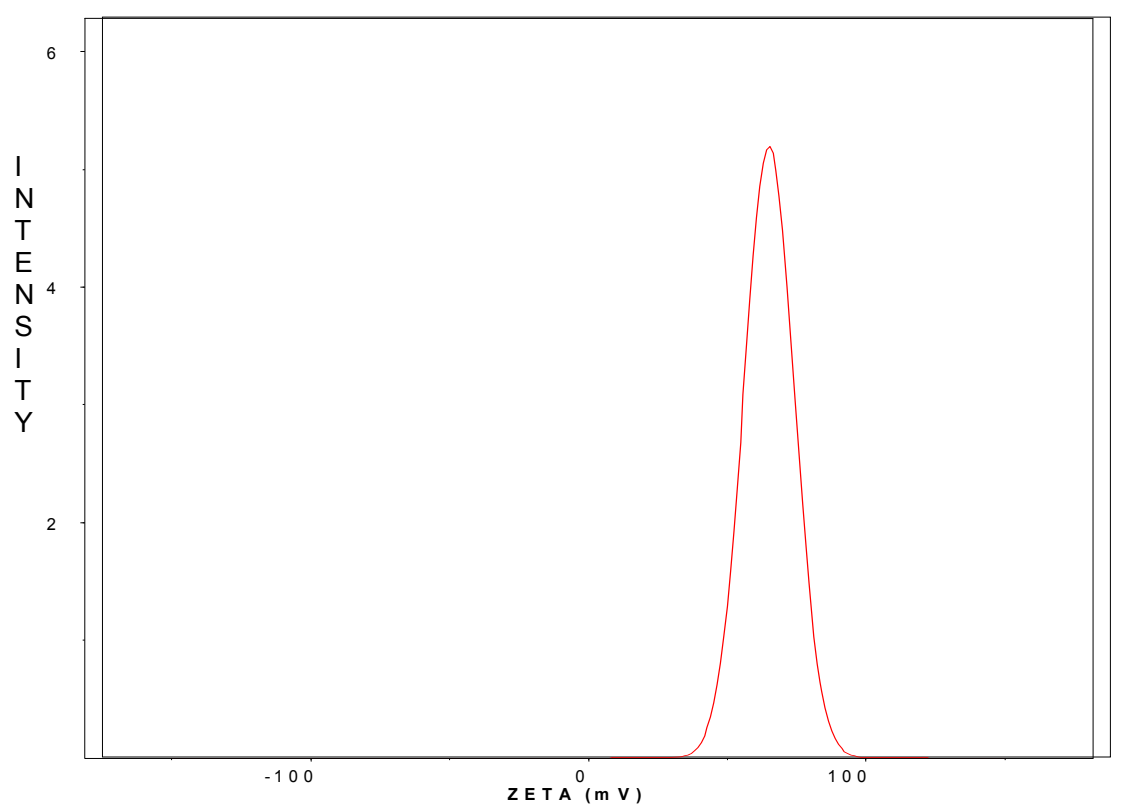

Figure 2 Particle size distribution of alumina slurry (see online version for colours)

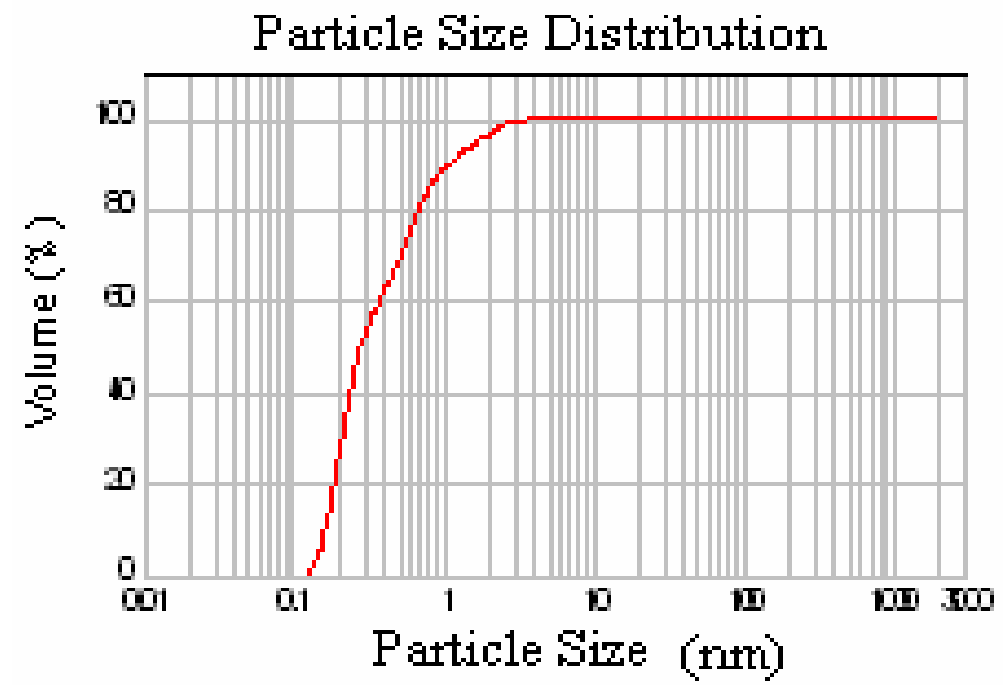


Figure 3 Pore size distribution of aluminas (see online version for colours)

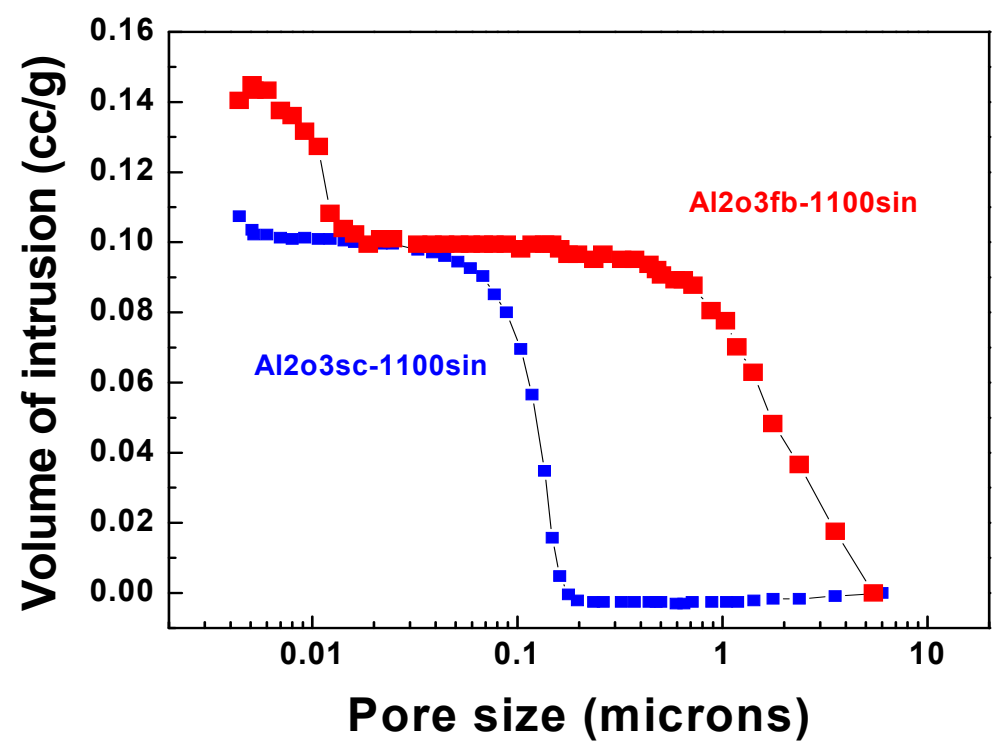

Figure 4 Zeta potential of silica sol at $\mathrm{pH}=3$ (see online version for colours)

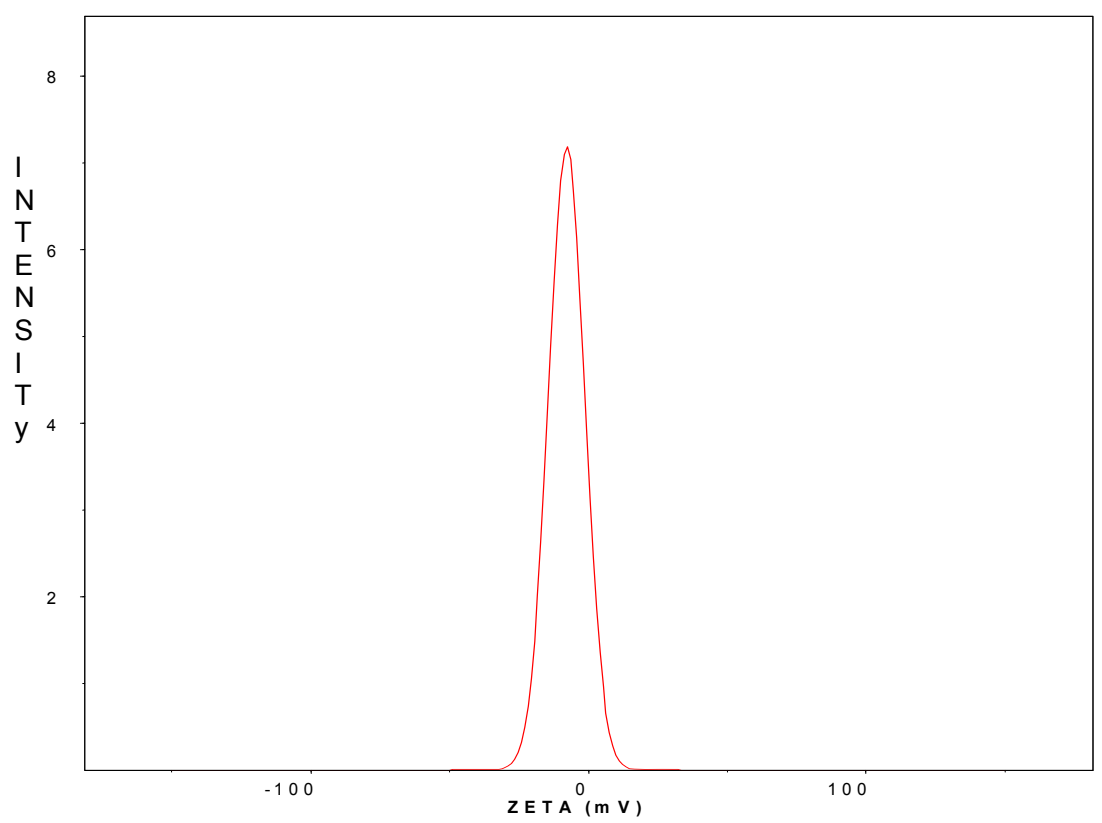


Figure 5 Microstructure of alumina fibre board

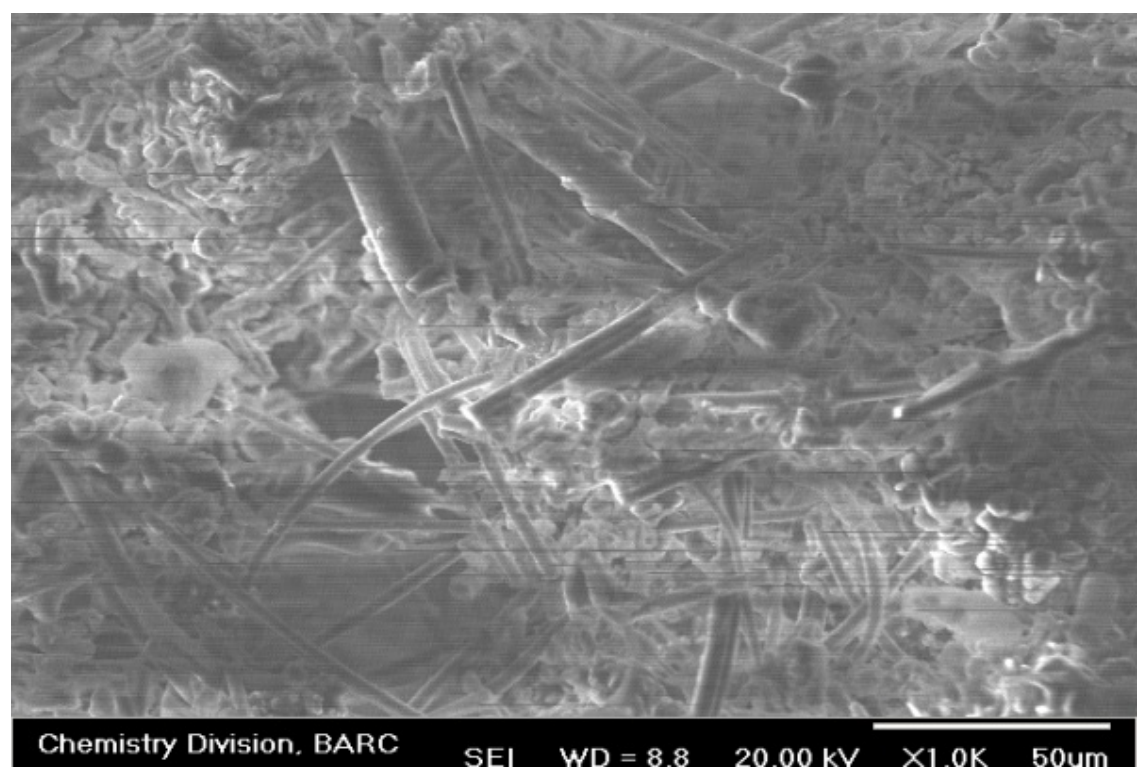

Figure 6 Microstructure of sintered alumina layer over alumina fibre board

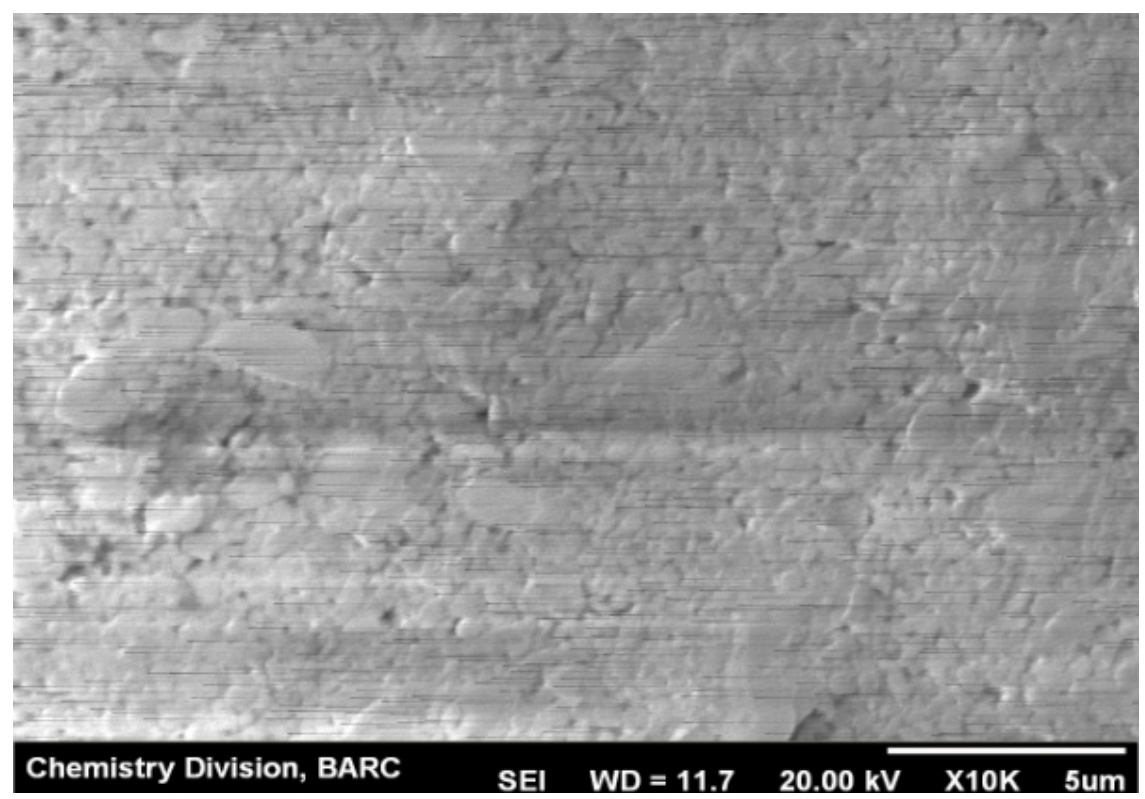


Figure 7 Microstructure of silica layer

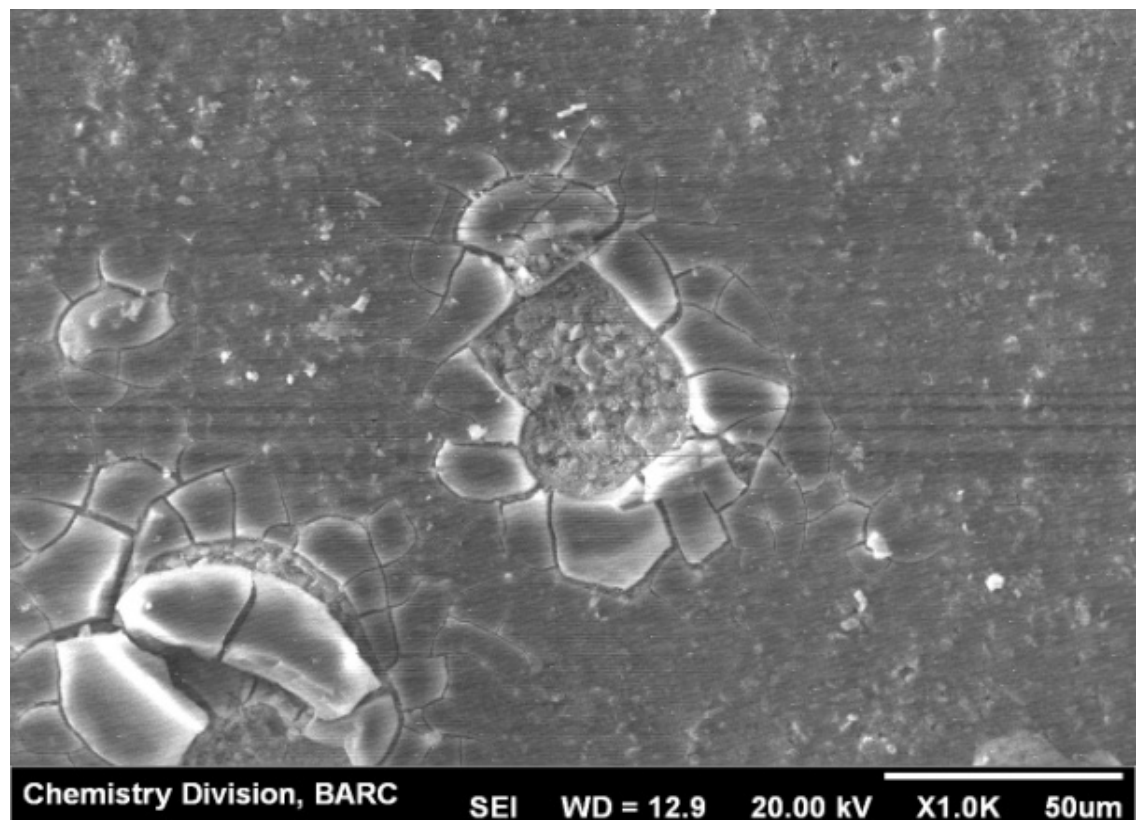

Figure 8 Cross section of alumina supported silica membrane

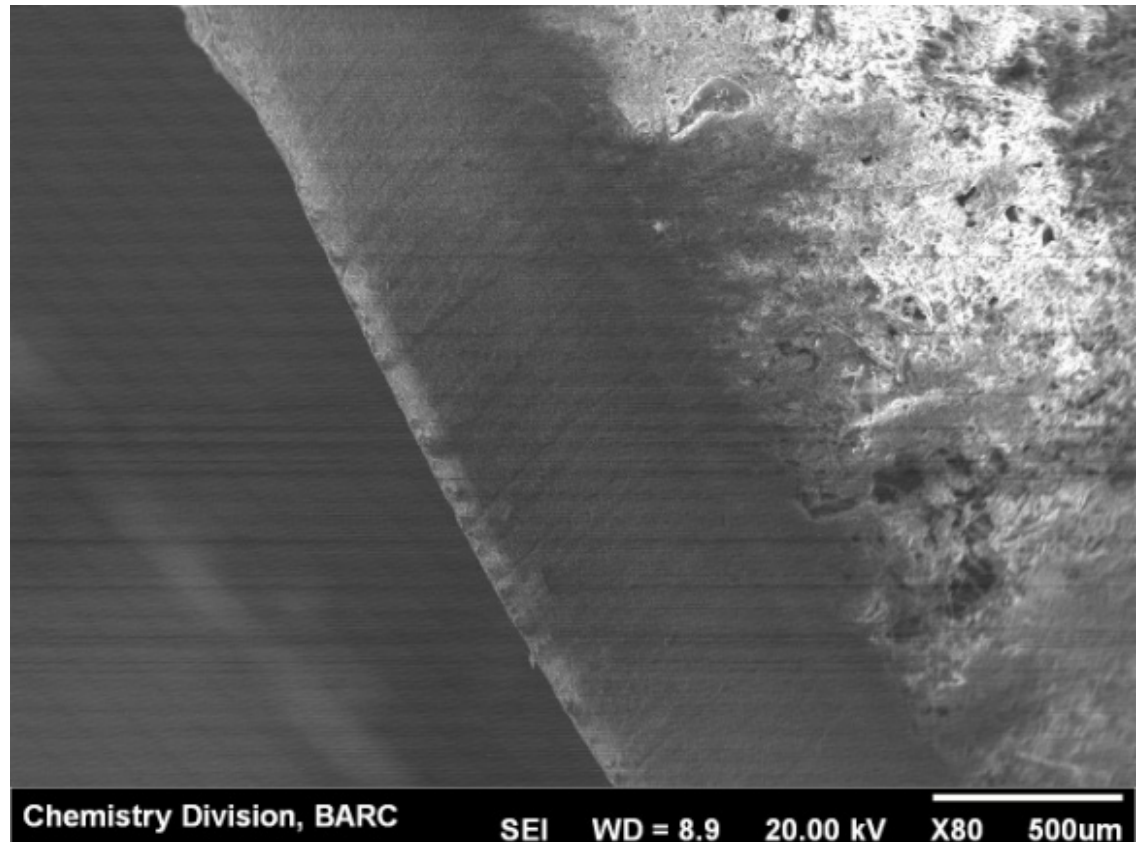

The graded porous structure was formed by dipping the fibre board (micro structure of alumina fibre board shown in Figure 5) in the alumina slurry and infiltrating it for varying periods of time followed by withdrawal at a constant rate of $30 \mathrm{~cm}$ per minute. 
Due to the capillary action of pores present in the fibreboard, the alumina slurry got infiltrated and formed stongly adherent thick films of alumina (micro structure of alumina over alumina fibre board shown in Figure 6) with thickness varying up to $2 \mathrm{~mm}$. As-grown support was sintered at $1000^{\circ} \mathrm{C}$ and was used as substrate for microporous silica membranes. Conditions were optimised for sintering of the layer to improve adherence and formation of the graded composite structure without cracks. Formation of silica film (with pores in the size of about $1.6 \mathrm{~nm}$ ) on the alumina support with graded porous structure was studied using a silica sol. Silica membrane (micro structure of silica shown in Figure 7) was prepared by dipping the slurry-formed-alumina-surface supported on fibre board for two minutes in the silica sol, followed by drying/gelling and heat treatment at $600^{\circ} \mathrm{C}$ at a heating rate of $0.5^{\circ} \mathrm{C} / \mathrm{min}$ and a soaking time of two hours. The average pore diameter was found to be about $1.6 \mathrm{~nm}$ by BJH method. It is clear from Figure 7 that the layer of silica grown is having cracks, which was found to get healed up with repeated coating. A detailed study on the surface morphology and cross-sections of monoliths and membranes (Figure 8) were studied by scanning electron microscope. The studies clearly reveal the development of graded structure wherein the three distinct layers of alumina fibre board, thick and dense alumina layer and thin silica layer are remarkably identified.

\section{Road-map envisaged}

The hydrogen permselectivity of the membrane will be studied using gas-chromatograph. The major issue to be addressed is the stability of the membrane (Hwang et al., 2003) material in the environment of $\mathrm{HI}, \mathrm{I}_{2}$ and water. Keeping this in view it is proposed to keep the membrane samples in the $\mathrm{HI}_{\mathrm{x}}$ environment at different set temperatures like $100^{\circ} \mathrm{C}, 200^{\circ} \mathrm{C}, 300^{\circ} \mathrm{C}, 400^{\circ} \mathrm{C}$ and $500^{\circ} \mathrm{C}$ including room temperature for different set hours varying up to days. Thereafter the microstructural characterisations of membrane samples will be carried out to assess the generation of cracks/defects in the separating layer. XRD studies are also proposed to see if there is any degradation of silica phase. The findings from gas permeation studies would help us confirm the effect of $\mathrm{HI}_{\mathrm{x}}$ environment on membrane structure and morphology. After the stability of alumina supported silica membranes in high temperature and highly corroding environment is ascertained (Kubo et al., 2003; Lai, 1990), efforts will be undertaken for growth of a tubular silica membrane reactor (Nomura et al., 2004) with impregnation of catalyst, which can be of practical use in a scaled up $\mathrm{HI}_{\mathrm{x}}$ processing section. In this way we believe there could be drastic decrease in the thermal load in the distillation column, making the overall efficiency improved.

\section{Conclusions}

The authors believe, amongst so many issues related to material development, suitable membrane development is one of the most critical associated with the S-I thermochemical process. It is conceived that the incorporation of hydrogen permselective membrane reactor can help in the enhancement of overall thermal efficiency of the process. The authors successfully developed an alumina supported silica membrane of graded porosity using sol-gel processing. The parameters for development of a stable sol 
solution and gelling conditions were optimised. The developed membranes were characterised using scanning electron microscope and BET surface area analyser. Presently the hydrogen permselectivity behaviour of the as-grown membrane is being assessed before a suitable membrane reactor is being designed.

\section{References}

de Vos, R.M. and Verweij, H. (1998) Science, Vol. 279, p.1710.

Goldstein, S. et al. (2005) Int. J. Hydrogen Energy, Vol. 30, p.619.

Hwang, G. et al. (2003) J. of Membrane Science, Vol. 215, pp.293-302.

Kubo, S. et al. (2003) Paper presented at the Proceedings of the 2nd Topical Conference on Fuel Cell Technology, AIChE 2003 Spring National Meeting.

Lai, G.Y. (1990) High-Temperature Corrosion of Engineering Alloys, ASM International, Materials Park, $\mathrm{OH}$.

Nomura, M. et al. (2004) Industrial and Engineering Chemistry Research, Vol. 43, pp.5874-5879.

Nomura, M. et al. (2005) Int. J. Hydrogen Energy, Vol. 30, p.1465.

Pakizeh, M. et al. (2007) Int. J. Hydrogen Energy, Vol. 32, p.1825. 